\title{
Peer review practicalities in clinical medicine
}

This article was published in the following Dove Press journal:

Advances in Medical Education and Practice

12 October 2010

Number of times this article has been viewed

\section{Matthew J Metcalfe' \\ MAL Farrant ${ }^{2}$ \\ JM Farrant ${ }^{3}$}

'Department of Vascular Surgery, Imperial College NHS Trust, St Mary's Hospital, London, UK; ' ${ }^{2}$ Department of Anaesthesia, Poole Hospital NHS Foundation Trust, Poole Hospital, Dorset, UK; ${ }^{3}$ Department of Radiology, Royal Free Hampstead NHS Trust, Royal Free Hospital, London, UK
Correspondence: Matthew J Metcalfe Department of Vascular Surgery, Mary Stanford Wing, St Mary's Hospital, Praed St, Paddington, London W2 INY, UK

Tel +44207886 6666

Fax +44203312 2216

Email mmetcalfe@doctors.org.uk
Abstract: Peer review processes in teaching requires a reviewer to observe a teacher's practice in a planned manner. Conversation between the two enables the teacher to reflect on their own teaching, promoting self-improvement. Although a central part of the teaching process, and despite its crucial role in continuing professional development, peer review is not widely practiced in hospital settings. This article explains the process and its benefits. Practical implementations of the process in busy clinical settings are suggested. Its evaluation and incorporation into undergraduate learning and postgraduate clinical practice are described. With enthusiastic support for colleagues and allowances for its implementation, it should become part of the regular teaching practice, improving the quality of teaching delivered.

Keywords: teaching, education, clinical practice, peer review

\section{Introduction}

Peer observation has only become a feature of university practice over the last couple of decades. ${ }^{1}$ The concept of peer reviewing a teacher's performance, or peer observation of teaching, is a mechanism whereby both teaching and learning can be improved through reflection. ${ }^{2}$ Osterman and Korttamp ${ }^{3}$ defined reflective practice as a means by which practitioners can develop a greater self-awareness about the nature and impact of their performance, creating opportunities for professional growth and development. Peer review is a means of creating a reflective study of the teaching process, allowing doctors who teach to view their roles as educators, rather than merely passing on their knowledge. The process should not be judgmental, but developmental. It holds advantages for both the teacher being reviewed and the peer reviewer. As professionals in the National Health Service, we are constantly under pressure to adapt and demonstrate accountability. Peer review can facilitate professional accountability and support individual professional evolution. ${ }^{4}$

Numerous groups of students have been taught around patients' beds by the doctor, but on how many occasions does another doctor join the group as a peer reviewing colleague? How often does a teacher invite another colleague to sit in on a tutorial or practical session and ask for ideas on developing their teaching methods, having had an initial briefing and planning of the review process? Plenty of teaching opportunities exist in both clinical and nonclinical environments. Forward planning of a peer review process requires extra commitment but should be self-rewarding. Self-directed planning of peer reviews needs promoting throughout our practice and should almost be compulsory. Reviewing one's teaching is essential to ensure that the preparation, approach, and delivery of the teaching are appropriate. Reviewing and revising 
our techniques should improve the quality of the teaching delivered.

\section{Discussion of the peer review process}

A good teacher may be intuitive, imaginative, evaluative, a good listener, and willing to change. Peer review reflection involves the process of teaching and the thinking behind it. ${ }^{5,6}$ Observations should be formative rather than summative. ${ }^{7}$ The aim of peer review is not to grade the teacher or the lesson, nor to highlight teachers' shortcomings but to reflect on the teaching practice and encourage new insights into the teacher's practice.

Peer review practice should be a developmental process. Benefits to peer review practice include the sharing of good teaching practice, collaboration with others, exploring new ideas and innovations and enabling the teacher to stand back and observe one's own practice. Constructive feedback from peers can increase trust and help build positive working relationships. A reflective attitude is required from the reviewee, and an open, honest dialog between reviewer and reviewee should occur. Based on the conversation theory of teaching, construction of knowledge about the success of the teaching itself is based on the conversation and negotiations between reviewee and reviewer. ${ }^{8}$ One person's interpretation of another person's behavior and their subsequent conversation is the basis on which the reviewee can learn. Hidden teaching behaviors and methods to improve negative aspects may be revealed and discussed. The reviewee can request certain aspects of the teaching to be focused on, as ultimately the reviewee should feel they have control of this process, allowing for a more open, constructive dialog between the two.

The peer review process can be a stepwise process. First, the reviewer and the reviewee discuss the peer review process and any ground rules that may apply, such as confidentiality. They should discuss the objectives, the types of teaching and learning activity taking place, and the number and academic level of the learners. Specific areas for reviewer's focus and data collection methods are also discussed. The data is then collected during observation of the teaching exercise. They must collect evidence to explain particular observations of the teaching practice and to explain how an alternative technique may be beneficial. After collecting the data, the important reflective dialog can occur. The reviewer should help the reviewee to explore his or her practice; a questiononly approach from the reviewer is often encouraged. Critical feedback, presented constructively, can encourage professional development. ${ }^{9}$ Teachers need to be able to engage others in reflective practice, and the feedback sessions should act as a trigger for enhancing this to both reviewer and reviewee. ${ }^{6,10}$ An acknowledgment of contributions to the process by each other is important in concluding the review, confirming an understanding of the reflection and encouraging future reviews.

\section{Practical applications}

Peer review should occur in a number of environmental settings to offer the reviewee reflection in all their teaching areas. These may include ward rounds, group tutorials, lectures, operating theatres, outpatient clinics, and teaching courses. Doctors are constantly teaching others throughout their daily work, though constant shadowing by the reviewee is clearly not feasible. Peer review occurs in the normal environment of the teaching itself, consisting of both a physical and a social context. This supports learning with a shared cognition theory, in which the teaching environment itself is the focus, such that the reviewer can highlight environmental issues for the reviewee to reflect on while observing the teaching in its natural setting. ${ }^{11}$

Few doctors have had specific training in teaching. It is not an obligatory undergraduate topic nor is it a part of the membership and fellowship exams. Postgraduate certificates, diplomas, and degrees now exist in medical education, but these are for the enthusiast. Peer review indications, applicability, and advantages need to be highlighted to others in the profession for it to be enthusiastically undertaken. Ideally, reviewers should undergo training, but this requires trainers, time, and money. Given that nearly all doctors are involved in teaching during their obligatory early years in clinical practice, it would seem appropriate that peer review is introduced to them during undergraduate training. Undergraduates could then gain experience at being both the reviewee and the reviewer and have an understanding for when the process is required during their clinical practice. This would encourage them to continue a known and well-rehearsed activity.

Practical difficulties with peer review include the time required for the process (preplanning, the teaching itself, and the reflective review after) and the availability of the extra teacher. This may require twice the amount of time the teaching itself takes. Feedback and reflection time must occur soon after the teaching itself. If teaching sessions were better timetabled and adhered to, then this could allow for a dedicated peer review at each session, as would enable forward planning of the review. Peer review should be included in the activities of the professional as it aims to enhance their 
teaching successes. During postgraduate training and after completion of specialist training, doctors should be encouraged to collect reflective feedback discussion data both as a reviewer and as a reviewee from their peer review sessions. This would encourage the review process, improving the doctors' familiarity with it. These could be incorporated into an obligatory revalidation process and become a requirement for the core trainee's portfolio.

Limiting junior doctor's time to 48 hours per week spent on the ward, a result of the much criticized European Working Time Directive, may discourage juniors from peer reviewing as they will not have the time to spend reviewing their colleagues teaching, let alone find another colleague actually at work due to the shift pattern of their working week. Their already congested clinical timetable lowers the priority given to reflective thinking. Teaching is often carried out in addition to routine clinical work, so a peer review process would need to be seen as time effective to appeal to them.

Personality conflicts between the reviewer and the reviewee may disrupt a learning discussion, though they must accept that it is a learning process for both. Personal relationships may complicate the feedback process, so should unknown outside peers be used? Jarzabkowski and Bone ${ }^{12}$ commented that peer review can arouse fear and resistance. Slight distancing, using peers who the reviewee has little daily interaction with, may have advantages when receiving and handling critical feedback. Trust is required for successful reflection, so repeatedly using the same partnership over time may help build this. ${ }^{13}$ To reduce conflicts between reviewer and reviewee, a trio of reviewers can be arranged. Reviewer A observes B, who observes $\mathrm{C}$, who observes A. This should reduce petty retaliation and avoid grudges that could occur if reflection is poorly carried out.

The level of activity of the reviewer must be considered. Should they play a passive role at the back of the lecture room, an active role among a tutorial group, a shadowing role of the teacher following his or her footsteps around the classroom, or a free wandering role whereby the reviewer observes freely from all around the room?

Various structured reflection processes (Johns and Graham, ${ }^{14}$ Benner, ${ }^{15}$ Gibbs, ${ }^{16}$ and Boud et $\mathrm{al}^{17}$ ) can be used to guide the reviewer during the peer review. Reflective assessment forms or check lists, structured on the previously mentioned processes, could be completing during the observation, guiding the reviewer. Leung et $\mathrm{al}^{18}$ defined reflective learning as four interrelated cognitive processes: Interpretation, Validation, Generalization, and Change. Each of these processes has three cognitive tasks that can be observed, thus providing a template for reflective practice learning, aiding both the reviewer and the reviewee. Its evaluation enables external review of the peer review process, ensuring a satisfactory level of reflection was undertaken. It may also support a grading of the process and enable its use in competency based assessments.

\section{Conclusion}

Continuing professional development has important individual and professional roles. Developing a habit of critical reflection is thought to be integral to professionalism. The support and resources needed to develop these skills must be available to maintain the quality of the professionalism. ${ }^{4}$ Financial assistance, education, and local support from colleagues and peers are all requirements for reflective peer review practice.

The process should be viewed as part of the teaching itself and of benefit to the reviewee. Peer review should not be unexpected, but a welcomed routine activity. Enthusiastic use of the process should provide a framework for improving ones teaching practice and allow for a more productive reflection that benefits all.

\section{Disclosure}

The authors report no conflicts of interest in this work.

\section{References}

1. Shortland S. Peer observation: a tool for staff development or compliance? J Further High Educ. 2004;28(2):219-228.

2. Lublin J. A guide to peer review of teaching. Tasmania: University of Tasmania. Published 2002. Available from: www.utas.edu.au/tl/ improving/peerreview/

3. Osterman KF, Korttamp RB. Reflective Practice for Educators: Improving Schooling Through Professional Development. Newbury Park, CA Corwin Press, Inc; 1993.

4. Peel D. Dual professionalism: facing the challenges of continuing professional development in the workplace? Reflective Practice. 2005;6(1):123-140.

5. Kuit JA, Gill R. Experiences of reflective teaching. Active Learn High Educ. 2001;2(2):128-142

6. Hammersley-Fletcher L, Orsmond P. Reflecting on reflective practices within peer observation. Stud High Educ. 2005;30(2):213-224.

7. Fullerton H. Observation of teaching. In: Fry H, Ketteridge S, Marshall S, editors. A Handbook for Teaching and Learning in Higher Education: Enhancing Academic Practice. London: Kogan Page; 1999.

8. Gordon Pask. The Cybernetics of Human Learning and Performance. London: Hutchinson; 1975.

9. Hogston R. Evaluating quality nursing care through peer review and reflection: the findings of a qualitative study. Int J Nurs Stud. 1995; 32(2):162-172.

10. Brockbank A, McGill I. Facilitating Reflective Learning in Higher Education. 1st ed. Buckingham: Open University Press; 1998.

11. Kumar VS. Computer-supported collaborative learning: issues for research. Department of Computer Science, University of Saskatchewan. 1996.

12. Jarzabkowski P, Bone Z. A 'How-to' guide and checklist for peer appraisal of teaching. Innovat Educ Teach Int. 1998;35(1): $177-182$. 
13. Farrell TSC. Tailoring reflection to individual needs: a TESOL case study. J Educ Teaching. 2001;27(1):23-38.

14. Johns C, Graham J. Using a reflective model of nursing and guided reflection. Nurs Stand. 1996;11(2) 34-38.

15. Benner P. From novice to expert: excellence and power in clinical nursing practice. Menlo Park, CA: Addison-Wesley; 1984.

16. Gibbs G. Learning by Doing: A Guide to Teaching and Learning Methods. Oxford: Further Education Unit, Oxford Brookes University; 1988.
17. Boud D, Keogh R, Walker D, editors. Reflection: Turning Experience into Learning. New York: Kogan Page; 1985.

18. Leung KH, Pluye P, Grad R, Weston C. A reflective learning framework to evaluate CME effects on practice reflection. J Contin Educ Health Prof. 2010;30(2):78-88.

\section{Publish your work in this journal}

Advances in Medical Education and Practice is an international, peerreviewed, open access journal that aims to present and publish research on Medical Education covering medical, dental, nursing and allied healthcare professional education. The journal covers undergraduate education, postgraduate training and continuing medical education including emerging trends and innovative models linking education, research, and healthcare services. The manuscript management system is completely online and includes a very quick and fair peer-review system. Visit http://www.dovepress.com/testimonials.php to read real quotes from published authors.

Submit your manuscript here: http://www.dovepress.com/advances-in-medical-education-and-practice-journal 